\title{
Decrease in Self-Efficacy for Exercise at 12 Weeks after Exercise Education in Diabetic Patients
}

\author{
Nobumasa Matsui, Kei Washida, Morio Shoji, Dai Nakaizumi, Takashi Kitagawa, Shigeru Terada, \\ Keita Uchiyama
}

Department of Rehabilitation, Japanese Red Cross Kanazawa Hospital, Kanazawa, Japan

Email: mnobu12@gmail.com

How to cite this paper: Matsui, N., Washida, K., Shoji, M., Nakaizumi, D., Kitagawa, T., Terada, S. and Uchiyama, K. (2017) Decrease in Self-Efficacy for Exercise at 12 Weeks after Exercise Education in Diabetic Patients. Health, 9, 649-656.

https://doi.org/10.4236/health.2017.94046

Received: February 16, 2017

Accepted: April 15, 2017

Published: April 18, 2017

Copyright (C) 2017 by authors and Scientific Research Publishing Inc. This work is licensed under the Creative Commons Attribution International License (CC BY 4.0).

http://creativecommons.org/licenses/by/4.0/

\begin{abstract}
The purpose of this study was to investigate whether self-efficacy for exercise decreased 12 weeks after educational intervention in diabetic patients and whether this had an effect on glycemic control. Thirty-eight diabetic patients underwent a 2-week educational program and were then followed for 12 weeks after discharge. The intervention program was delivered by several types of medical professionals. Lectures on exercise were given by a physical therapist, who tailored exercise instructions for individual patients. The assessment of self-efficacy for exercise was performed using a scale from a previous study, modified for Japanese people. The scale consisted of four sub-items: physical fatigue, mental stress, lack of time, and poor weather. Measurements were performed at the time of discharge and 12 weeks after discharge. Glycated hemoglobin (HbAlc) levels were assessed as an index of glycemic control, and diabetic status and social status factors were recorded. The physical fatigue and lack of time components of the self-efficacy for exercise scale were significantly decreased 12 weeks after discharge. Positive correlations were found between $\mathrm{HbAlc}$ levels at 12 weeks and duration of diabetes, number of educational admissions, and presence of diabetic retinopathy. The results suggest that the factors that are difficult to reproduce during hospital education (physical fatigue and lack of time) are the ones that decrease after discharge. To clarify the relationship between changes in self-efficacy for exercise and glycemic control, further studies with an extended follow-up period ( 24 weeks or 48 weeks) are needed.
\end{abstract}

\section{Keywords}

Self-Efficacy, Exercise, Glycated Hemoglobin 


\section{Introduction}

Self-efficacy is the belief of an individual in his/her ability to perform a particular activity and influence the level of effort and perseverance in spite of difficulties. In the prestigious work of Bandura, self-efficacy is a psychological factor affecting behavioral change [1]. Social cognitive theory (SCT), which is based on self-efficacy, can contribute to changes in lifestyle and weight loss in obesity [2]. In diabetic patients, a few studies have suggested that interventions based on SCT increase self-care levels and improve glycemic control [3] [4].

Self-efficacy for exercise has been shown to increase physical activity (PA) levels in diabetic patients [5]. As a result of intervention-based SCT, improvements in PA levels are maintained for 6 - 12 months [6]. Thus, higher self-efficacy for exercise increases PA levels, and the effect lasts for a period of time. In type 2 diabetic patients, elevated levels of PA affect glycemic control [7]. Interventions to reinforce self-efficacy for exercise play an important role in exercise therapy for diabetic patients. However, there are few studies investigating the relationship between changes in self-efficacy for exercise and glycemic control. If we could immediately recognize the decrease in self-efficacy for exercise, we would be able to determine the appropriate frequency of intervention after exercise education. Therefore, this study may contribute to the construction of exercise therapy programs for diabetic patients by incorporating socio-psychological factors.

We therefore hypothesized that self-efficacy for exercise decreases in the 12 weeks after an educational intervention in diabetes patients. In addition, we hypothesized that poor glycemic control correlates with decrease in self-efficacy for exercise. To test this hypothesis, the change in self-efficacy for exercise 12 weeks after an educational intervention was evaluated, and the correlation between self-efficacy for exercise and glycemic control was examined.

\section{Methods}

\subsection{Subjects}

The subjects were 48 diabetic patients admitted to the Japanese Red Cross Kanazawa Hospital between March 2015 and September 2016. The age of the subjects was 20 years or older. All the subjects were hospitalized for improvement of glycemic control and diabetes education consisting of a 2-week educational program. They were then followed up 12 weeks after discharge. Patients were excluded if they could not be followed up after 12 weeks or were hospitalized for a disease not related to diabetes. Two patients dropped out of treatment. Three were hospitalized for the treatment of other diseases. Three were treated by family doctors. Two patients moved to other areas. Thirty-eight subjects were Japanese living in the vicinity of Kanazawa City. The intervention program was performed by a doctor, a nurse, a dietician, a medical technologist, a pharmacist, and a physical therapist. The exercise therapy was performed by the physical therapist. The exercise therapy consisted of three parts, lectures on exercise, tailored individual counseling, and exercise practices, according to each patient's 
individual lifestyle to enable them to continue the exercises after discharge. We particularly focused on instructions for exercising in poor weather, because of the high annual precipitation in the Hokuriku region.

Information on diabetes status (i.e., status of vascular complications, injecting insulin, education hospitalization history) and social status (i.e., living with family, working full time or part time) was collected. Diabetic polyneuropathy was defined as an abnormality in nerve conduction velocity or attenuation of protective sensation determined by 4.56 Semmes-Weinstein monofilament test. Retinopathy was defined as more than simple retinopathy. Diabetic nephropathy was defined as a urinary albumin/creatinine ratio of above $30 \mathrm{mg} / \mathrm{g}$ creatinine. $\mathrm{HbA1c}$ levels were measured at admission and at 12 weeks after discharge, as an index of glycemic control. All patients provided written informed consent before enrollment.

\subsection{Self-Efficacy for Exercise}

Self-efficacy for exercise was assessed using a scale from a previous study [8], modified for Japanese patients. The scale was a self-administered questionnaire and consisted of four sub-items: I am confident I can participate in regular exercise when I am tired (physical fatigue), when I am in a bad mood (mental stress), when I feel I do not have the time (lack of time), and when it is raining or snowing (poor weather) [9]. A five-point scale was used to rate each item (1 = I am not at all confident to $5=\mathrm{I}$ am very confident). The total possible score ranged between 4 and 20 points. Measurements were performed at the time of discharge and 12 weeks after discharge.

\subsection{Statistics}

For each variable, including patient characteristics and HbAlc levels, normal distribution was confirmed using the Kolmogorov-Smirnov test. The paired t-test was performed to assess differences in the total self-efficacy score between discharge and after 12 weeks. The Wilcoxon signed-rank test was performed to compare sub-item scores. In a correlation analysis, the correlation ratio was calculated for variables on the nominal scale, Pearson's correlation coefficient was calculated for variables with normal distribution, and Spearman's correlation coefficient was calculated for variables without a normal distribution. The significance level was set at $\mathrm{p}<0.05$.

\section{Results}

The patient characteristics are shown in Table 1. This was the first educational program for $55.3 \%$ of patients, accounting for more than half of the patients. The average of duration of diabetes was $7.9( \pm 7.3)$ years; the patients with short and long durations were mixed. Table 2 shows the total self-efficacy and sub-item scores at discharge and 12 weeks after discharge. Scores for physical fatigue and lack of time at 12 weeks after discharge were significantly lower than those at discharge. The scores in the other sub-items and total scores did not 
change. Statistically significant positive correlations were found between $\mathrm{HbAlc}$ levels at 12 weeks after discharge and duration of diabetes, first education program, and presence of diabetic retinopathy (shown in Table 3 ).

\section{Discussion}

Although there was no difference in the total self-efficacy score between the time of discharge and 12 weeks later, the scores for physical fatigue and lack of time decreased significantly. Previous studies have indicated that being busy [10] [11] [12] and fatigued [13] affect PA and self-efficacy. However, other studies have shown that social support from families [12] [14] and spouses [10], environmental factors such as climate and traffic [10] [15] [16], and stressful life events [17] are related to PA. Thus, a multifaceted approach is important in exercise

Table 1. Patient characteristics.

\begin{tabular}{ccc}
\hline Characteristic & n & Means \pm SD or \% \\
\hline Age (years) & 38 & $61.0 \pm 12.6$ \\
Sex (male/female) & $21 / 17$ & \\
Body-mass index $\left(\mathrm{kg} / \mathrm{m}^{2}\right)$ & 38 & $27.3 \pm 7.0$ \\
Type of diabetes (type 1/type 2) & $2 / 36$ & \\
Duration of diabetes (years) & 38 & $7.9 \pm 7.3$ \\
First educational program & 21 & $55.3 \%$ \\
Diabetic polyneuropathy & 16 & $42.1 \%$ \\
Diabetic retinopathy & 7 & $18.4 \%$ \\
Diabetic nephropathy & 6 & $15.8 \%$ \\
History of cerebrovascular disease & 4 & $10.5 \%$ \\
History of coronary artery disease & 5 & $13.2 \%$ \\
Injecting insulin & 15 & $39.5 \%$ \\
Living with family & 32 & $84.2 \%$ \\
Working full time or part time & 17 & $44.7 \%$ \\
HbAlc at admission (\%) & 38 & $9.8 \pm 2.1$ \\
HbA1c at 12 weeks after discharge (\%) & 38 & $7.2 \pm 1.1$ \\
\hline
\end{tabular}

HbAlc, glycated hemoglobin; SD, standard deviation.

Table 2. Self-efficacy for exercise scores.

\begin{tabular}{cccc}
\hline Score & At discharge & 12 weeks after discharge & p value \\
\hline Total score & $15.3 \pm 3.0$ & $14.4 \pm 4.0$ & 0.12 \\
Physical fatigue (5/4/3/2/1) & $\underline{11 / 20 / 4 / 3 / 0}$ & $\underline{9 / 16 / 3 / 8 / 2}$ & $\underline{0.02}$ \\
Mental stress (5/4/3/2/1) & $6 / 23 / 4 / 4 / 1$ & $10 / 13 / 8 / 5 / 2$ & 0.48 \\
Lack of time(5/4/3/2/1) & $\underline{7 / 21 / 5 / 5 / 0}$ & $\underline{8 / 15 / 4 / 7 / 4}$ & $\underline{0.04}$ \\
Poor weather (5/4/3/2/1) & $9 / 18 / 3 / 7 / 1$ & $12 / 15 / 3 / 7 / 1$ & 0.67
\end{tabular}


Table 3. Correlations between HbAlc levels at 12 weeks after discharge and patient characteristics.

\begin{tabular}{|c|c|}
\hline Characteristic & Correlation coefficient \\
\hline Age & 0.31 \\
\hline Sex & 0.05 \\
\hline Body-mass index & 0.00 \\
\hline Type of diabetes & 0.09 \\
\hline Duration of diabetes & $0.53 \dagger \dagger$ \\
\hline First educational program & $0.51 \dagger \dagger$ \\
\hline Diabetic polyneuropathy & 0.02 \\
\hline Diabetic retinopathy & $0.40 \dagger$ \\
\hline Diabetic nephropathy & 0.06 \\
\hline History of cerebrovascular disease & 0.11 \\
\hline History of coronary artery disease & 0.14 \\
\hline Injecting insulin & 0.01 \\
\hline Living with family & 0.11 \\
\hline Working full time or part time & 0.14 \\
\hline HbAlc at admission & -0.09 \\
\hline Total score of self-efficacy for exercise at discharge & 0.05 \\
\hline Total score of self-efficacy for exercise at 12 weeks after discharge & -0.05 \\
\hline
\end{tabular}

$\dagger \mathrm{p}<0.05 ; \dagger \mathrm{p}<0.01$.

therapy. Our patients were instructed in exercise methods for poor weather and given advice about life events and utilization of social support. However, it is difficult to reproduce physical fatigue and lack of time during hospital education; therefore, patients may experience these issues for the first time after discharge, and this may explain why the physical fatigue and lack of time scores decreased in the 12 weeks after discharge. This suggests the necessity of interventions to reinforce self-efficacy for exercise to overcome physical fatigue and lack of time early after discharge.

$\mathrm{HbA1c}$ levels were correlated with duration of diabetes, first educational program, and diabetic retinopathy. It has been suggested that duration of diabetes, diabetic retinopathy [18], and treatment of diabetes (with or without insulin) [19] are related to HbA1c levels, and a relationship with self-efficacy has also been reported [20], [21]. However, in this study, there was no statistical relationship between $\mathrm{HbAlc}$ levels 12 weeks after discharge and the total self- efficacy score. The coefficient of variation of $\mathrm{HbAlc}$ level at 12 weeks was 0.15 , so this group of patients may have had low variability in glycemic control; therefore a tendency for self-efficacy for exercise to be related to HbAlc level may not have been found. In a similar study, Torimoto et al. reported a correlation between $\mathrm{HbA1c}$ levels at 12 weeks after discharge and duration of diabetes [22], and our results agree. In other words, these patients group were not special pa- 
tient groups. Therefore, we speculated that this result shows patient characteristics 12 weeks after exercise education.

A limitation of this study was the short follow-up period. Further studies extending the follow-up period to 24 or 48 weeks are needed. This may enable further changes in self-efficacy for exercise and glycemic control to be observed, and may clarify the relationship between them.

Since two patients who dropped out after discharge were not included in the analysis, another limitation of this study is the possibility of the patient group having a high self-efficacy for exercise. Moreover, since this study was performed at a single facility, we cannot exclude the influence of area-specific climatic conditions. In addition to longer-term study, it would be desirable to conduct a study at multiple hospitals that are providing exercise instruction during admission.

\section{Conclusion}

This study suggests that scores for self-efficacy-related factors that are difficult to reproduce during admission decrease after discharge. In order to clarify a relationship between changes in self-efficacy for exercise and glycemic control, further studies with follow-up periods of $24-48$ weeks are needed.

\section{Acknowledgements}

The authors thank Dr. Y. Nishimura for the excellent advice.

\section{References}

[1] Bandura, A.S. and Adams, N.E. (1977) Analysis of Self-Efficacy Theory of Behavioral Change. Cognitive Therapy and Research, 1, 287-310. https://doi.org/10.1007/BF01663995

[2] Teixeira, P.J., Carraça, E.V., Marques, M.M., Rutter, H., Oppert J.M., De Bourdeaudhuij, I., et al. (2015) Successful Behavior Change in Obesity Interventions in Adults: A Systematic Review of Self-Regulation Mediators. BMC Medicine, 13, 84. https://doi.org/10.1186/s12916-015-0323-6

[3] Norris, S.L., Lau, J., Smith, S.J., Schmid, C.H. and Engelgau, M.M. (2002) Self-Management Education for Adults with Type 2 Diabetes: A Meta-Analysis of the Effect on Glycemic Control. Diabetes Care, 25, 1159-1171. https://doi.org/10.2337/diacare.25.7.1159

[4] Ismail, K., Winkley, K. and Rabe-Hesketh, S. (2004) Systematic Review and Meta-Analysis of Randomised Controlled Trials of Psychological Interventions to Improve Glycaemic Control in Patients with Type 2 Diabetes. The Lancet (London, England), 363, 1589-1597. https://doi.org/10.1016/S0140-6736(04)16202-8

[5] Dutton, G.R., Tan, F., Provost, B.C., Sorenson, J.L., Allen, B. and Smith, D. (2009) Relationship between Self-Efficacy and Physical Activity among Patients with Type 2 Diabetes. Journal of Behavioral Medicine, 32, 270-277. https://doi.org/10.1007/s10865-009-9200-0

[6] Andersen, E., Burton, N.W. and Anderssen, S.A. (2012) Physical Activity Levels Six Months after a Randomised Controlled Physical Activity Intervention for Pakistani Immigrant Men Living in Norway. International Journal of Behavioral Nutrition 
and Physical Activity, 9, 47. https://doi.org/10.1186/1479-5868-9-47

[7] Umpierre, D., Ribeiro, P.A.B., Schaan, B.D. and Ribeiro, J.P. (2013) Volume of Supervised Exercise Training Impacts Glycaemic Control in Patients with Type 2 Diabetes: A Systematic Review with Meta-Regression Analysis. Diabetologia, 56, 242 251. https://doi.org/10.1007/s00125-012-2774-Z

[8] Marcus, B.H., Selby, V.C., Niaura, R.S. and Rossi, J.S. (1992) Self-Efficacy and the Stages of Exercise Behavior Change. Research Quarterly for Exercise and Sport, 63, 60-66. https://doi.org/10.1080/02701367.1992.10607557

[9] Oka, K. (2003) [Stages of Change for Exercise Behavior and Self-Efficacy for Exercise among Middle-Aged Adults]. Japanese Journal of Public Health, 50, 208-215.

[10] Grace, S.L., Barry-Bianchi, S., Stewart, D.E., Rukholm, E. and Nolan, R.P. (2007) Physical Activity Behavior, Motivational Readiness and Self-Efficacy among Ontarians with Cardiovascular Disease and Diabetes. Journal of Behavioral Medicine, 30, 21-29. https://doi.org/10.1007/s10865-006-9080-5

[11] Mansyur, C.L., Pavlik, V.N., Hyman, D.J., Taylor, W.C. and Goodrick, G.K. (2013) Self-Efficacy and Barriers to Multiple Behavior Change in Low-Income African Americans with Hypertension. Journal of Behavioral Medicine, 36, 75-85. https://doi.org/10.1007/s10865-012-9403-7

[12] Nies, M.A. and Motyka, C.L. (2006) Factors Contributing to Women's Ability to Maintain a Walking Program. Journal of Holistic Nursing, 24, 7-14. https://doi.org/10.1177/0898010105282520

[13] Focht, B.C., Knapp, D.J., Gavin, T.P., Raedeke, T.D. and Hickner, R.C. (2007) Affective and Self-Efficacy Responses to Acute Aerobic Exercise in Sedentary Older and Younger Adults. Journal of Aging and Physical Activity, 15, 123-138. https://doi.org/10.1123/japa.15.2.123

[14] Wenthe, P.J., Janz, K.F. and Levy, S.M. (2009) Gender Similarities and Differences in Factors Associated with Adolescent Moderate-Vigorous Physical Activity. Pediatric Exercise Science, 21, 291-304. https://doi.org/10.1123/pes.21.3.291

[15] Tucker, P. and Gilliland, J. (2007) The Effect of Season and Weather on Physical Activity: A Systematic Review. Public Health, 121, 909-922. https://doi.org/10.1016/j.puhe.2007.04.009

[16] Cleland, V.J., Ball, K., Salmon, J., Timperio, A.F. and Crawford, D.A. (2010) Personal, Social and Environmental Correlates of Resilience to Physical Inactivity among Women from Socio-Economically Disadvantaged Backgrounds. Health Education Research, 25, 268-281. https://doi.org/10.1093/her/cyn054

[17] Delahanty, L.M., Conroy, M.B., Nathan, D.M. and Diabetes Prevention Program Research Group (2006) Psychological Predictors of Physical Activity in the Diabetes Prevention Program. Journal of the American Dietetic Association, 106, 698-705. https://doi.org/10.1016/j.jada.2006.02.011

[18] Walraven, I., Mast, M.R., Hoekstra, T., Jansen, A.P., van der Heijden, A.A., Rauh S.P., et al. (2015) Distinct HbA1c Trajectories in a Type 2 Diabetes Cohort. Acta Diabetologica, 52, 267-275. https://doi.org/10.1007/s00592-014-0633-8

[19] Sartore, G., Chilelli, N.C., Burlina, S., Di Stefano, P., Piarulli, F., Fedele, D., et al. (2012) The Importance of HbAlc and Glucose Variability in Patients with Type 1 and Type 2 Diabetes: Outcome of Continuous Glucose Monitoring (CGM). Acta Diabetologica, 49, 153-160. https://doi.org/10.1007/s00592-012-0391-4

[20] Kavanagh, D.J., Gooley, S. and Wilson, P.H. (1993) Prediction of Adherence and Control in Diabetes. Journal of Behavioral Medicine, 16, 509-522.

https://doi.org/10.1007/BF00844820 
[21] Talbot, F., Nouwen, A., Gingras, J., Gosselin, M. and Audet, J. (1997) The Assessment of Diabetes-Related Cognitive and Social Factors: The Multidimensional Diabetes Questionnaire. Journal of Behavioral Medicine, 20, 291-312. https://doi.org/10.1023/A:1025508928696

[22] Torimoto, K., Okada, Y., Sugino, S. and Tanaka, Y. (2016) Determinants of Hemoglobin A1c Level in Patients with Type 2 Diabetes after In-Hospital Diabetes Education: A Study Based on Continuous Glucose Monitoring. Journal of Diabetes Investigation, early view. https://doi.org/10.1111/jdi.12589

\section{Scientific Research Publishing}

Submit or recommend next manuscript to SCIRP and we will provide best service for you:

Accepting pre-submission inquiries through Email, Facebook, LinkedIn, Twitter, etc. A wide selection of journals (inclusive of 9 subjects, more than 200 journals)

Providing 24-hour high-quality service

User-friendly online submission system

Fair and swift peer-review system

Efficient typesetting and proofreading procedure

Display of the result of downloads and visits, as well as the number of cited articles Maximum dissemination of your research work

Submit your manuscript at: http://papersubmission.scirp.org/

Or contact health@scirp.org 